\title{
Priscilla Rachel Oliveira Bastos
}

Inflamação sistêmica induzida por LPS em anuros da espécie Rhinella icterica: efeito sobre os mediadores inflamatórios citocinas, corticosterona e melatonina

Dissertação apresentada ao Instituto de Biociências da Universidade de São Paulo, para obtenção do Título de Mestre em Ciências, na Área de Fisiologia Geral.

Orientadora: $\operatorname{Prof}^{\mathrm{a}} \operatorname{Dr}^{\mathrm{a}}$ Zulma F. S. Ferreira.

Co-orientador: Prof. Dr. Fernando R. Gomes 


\section{FICHA CATALOGRÁFICA}

Oliveira-Bastos, Priscilla Rachel

Inflamação sistêmica induzida por LPS em anuros da espécie Rhinella icterica: efeito sobre os mediadores citocinas, corticosterona e melatonina.

Priscilla Rachel Oliveira Bastos; orientadora Zulma F. S. Ferreira. São Paulo, 2017. $83 \mathrm{f}$.

Dissertação (Mestrado) - Instituto de Biociências da Universidade de São Paulo.

Departamento de Fisiologia.

1. Rhinella icterica. 2. Corticosterona. 3. Melatonina.

I. Universidade de São Paulo. Instituto de Biociências. Departamento de Fisiologia. II. Título.

\section{COMISSÃO JULGADORA}

$\operatorname{Prof}(\mathrm{a}) . \operatorname{Dr}(\mathrm{a})$

Prof(a). Dr(a)
$\operatorname{Prof}(\mathrm{a}) . \operatorname{Dr}(\mathrm{a})$

Prof(a). Dr(a). 


\section{Lista de Abreviaturas}

$\alpha$

$\beta$

ACTH

AA-NAT

AFMK

AMK

ANOVA

ASMT

ATP

CBG

CORT

COX-2

CRH

DNA

DAMPs

ELISA

epm

GM-CSF

GR

HHA

IBAMA

IFNY alfa

beta

hormônio adrenocorticotrófico

enzima arilalquilamina $\mathrm{N}$-acetiltransferase

N1-acetil-N2-formil-5-metoxiquinuramina

$\mathrm{N}^{1}$-acetil-5-metoxiquinuramina

análise de variância

acetilmetil transferase

adenosina 5'-trifosfato

proteína de ligação de corticosterona

corticosterona

ciclo-oxigenase 2

hormônio liberador de corticotropina

ácido desoxirribonucléico

padrões moleculares associados a dano

ensaio imunoenzimático

erro padrão da média

fator estimulador de colônia de granulócitos macrófagos

receptor de glicocorticoide

eixo hipotálamo-hipófise-adrenal

Inst. Bras. do Meio Ambiente e dos Rec. Naturais Renováveis

interferon gama 


\begin{tabular}{|c|c|}
\hline IL-1 $\beta$ & interleucina 1 beta \\
\hline IL-2 & interleucina 2 \\
\hline IL-4 & interleucina 4 \\
\hline IL-6 & interleucina 6 \\
\hline IL-10 & interleucina 10 \\
\hline IL-12p70 & interleucina 12 p70 \\
\hline IL-17 & interleucina 17 \\
\hline IL-17A & interleucina $17 \mathrm{~A}$ \\
\hline iNOS & óxido nítrico sintase \\
\hline LPS & lipopolissacarídeo \\
\hline MAP & proteína ativada por mitógenos \\
\hline MCP1 & proteína quimiotáxica de monócito \\
\hline MCR2 & melanocortina 2 \\
\hline MT1 & receptor de melatonina 1 \\
\hline MT2 & receptor de melatonina 2 \\
\hline Mel1c & receptor de melatonina $1 \mathrm{c}$ \\
\hline NAS & N-acetilserotonina \\
\hline NF-KB & fator nuclear kappa B \\
\hline NO & óxido nítrico \\
\hline P450c11 & $11 \beta$-hydroxylase \\
\hline PAMPs & padrões moleculares associados a patógenos \\
\hline PBS & tampão fosfato salino \\
\hline PGE2 & prostaglandina E2 \\
\hline PNPP & p-nitrofenilfosfato \\
\hline PVC & policloreto de vinila \\
\hline
\end{tabular}


RNS

ROS

TLR-4

TLRs

TNF

ZT

mm e mg

nm

rpm

$\mu \mathrm{L}$ e $\mathbf{m L}$

$\mu \mathrm{M}$ e $\mathbf{m M}$ espécies reativas de nitrogênio

espécies reativas de oxigênio

receptor Toll-4

receptores Toll

fator de necrose tumoral

zeitgeber time

milímetros e miligramas, respectivamente

nanômetro

rotação por minuto

microlitro e milititro, respectivamente

micromolar e milimolar, respectivamente 


\section{INTRODUÇÃO}

Os anuros representam o grupo de anfíbios mais abundante, com cerca de 6777 espécies viventes (FROST, 2017) e também que apresenta maior distribuição geografica (VITT \& CALDWELL, 2009) são os anuros. Estes são popularmente conhecidos como sapos, rãs e pererecas. A maioria das espécies do grupo necessita da existência de corpos d'água para reproduzirse e desenvolver-se, apresentando um ciclo de vida bifásico, típico de anfíbios, por possuírem uma fase aquática e outra terrestre (REGUERA, 2012). Cabe destacar que na fase aquática, girinos apresentam hábito diurno de atividade (CONDEZ et al., 2009).

Um declínio populacional de anfíbios vem sendo reportado desde o início da década de 1970. Dentre as causas para esse fenômeno, têm se destacado a destruição do hábitat e a ocorrência de doenças infecciosas causadas por fungos como Chytridiomycota; Chytridiales (BERGER et al., 1998), bactérias patogênicas como Aeromonas hydrophilla (TAYLOR et al., 1999) e iridovírus (CUNNINGHAM et al., 1996). É interessante notar também a existência de variações interespecíficas na tolerância e resistência a patógenos (BRADFORD et al., 1994; CAREY, 1993) levantando a questão da necessidade de ampliar o conhecimento dos aspectos da imunidade inata nestes animais.

Neste trabalho, utilizamos como modelo a espécie Rhinella icterica (Ordem Anura; Família Bufonidade), cuja nomenclatura antiga é Bufo icterica (SPIX, 1982). É um sapo grande do grupo Rhinella marina (MACIEL et al., 
2010), onde o macho mede cerca de $98-130 \mathrm{~mm}$ e a fêmea, 110-165 mm. Essa espécie apresenta distribuição geográfica associada a ambientes florestados (Mata Atlântica), contudo, indivíduos da espécie são facilmente encontrados em áreas antropomorfizadas (MACIEL et al., 2010). Na América do Sul, podem ser encontrados desde o sudeste e sul do Brasil, até o norte da Argentina e leste do Paraguai. Esses animais possuem hábito terrícola, atividade noturna e como estratégias de defesa, inflam o corpo, se camuflam com o meio e possuem glândulas de veneno. A estação reprodutiva se dá de agosto a janeiro, meses que ocorrem os principais períodos de desova, e quando podemos encontrar animais vocalizando em riachos e em poças de água parada. A desova se dá por grandes cordões gelatinosos, com milhares de ovos escuros depositados em partes rasas da água durante o amplexo. Os indivíduos recém-metamorfoseados, medindo cerca de 9-10 mm, deixam o sítio reprodutivo em meados de novembro e dezembro ao mesmo tempo (MACIEL et al., 2010).

Inflamação sistêmica induzida por lipopolissacarídeo (LPS) em anfíbios

Pirógenos exógenos, como o lipopolissacarídeo (LPS), endotoxina purificada de um composto da parede celular de bactérias gram-negativas, como Escherichia coli, atuam como agentes estressores promovendo ativação da resposta imune inata (KLUGER, 1991).

A etapa inicial de reconhecimento do LPS envolve sua interação com a proteína LBP (do inglês, lypopolysaccharide binding protein), proteína 
solúvel encontrada no plasma que permite o transporte de LPS para a superfície das células. LPS exerce seus efeitos intracelulares através da ligação a receptores TLR-4 (do inglês, toll-like receptor 4) expressos na membrana celular (Figura 1). A ativação da casacata de sinalização intracelular envolve inicialmente o recrutamento de proteínas adaptadoras, como MyD-88 (do inglês, myeloid differentiation primary response gene 88) que recrutam adaptadores subsequentes, como IRAK (do inglês: IL-1 receptor-associated kinase) e TRAF6 (do inglês: TNF receptor-associated fator 6), formando complexos regulatórios ancorados ao receptor TLR4 . Como consequência, uma via de sinalização intracelular é iniciada e resulta na ativação do complexo de quinases IKK que catalisa a fosforilação da proteína inibitória $\mathrm{IKB} \alpha$ sinalizando para que esta proteína seja degradada por proteassomas. Após a degradação da proteína inibitória, dímeros do fator de transcrição nuclear kappa B (NF- $\kappa \mathrm{B})$ ficam livres no citoplasma para

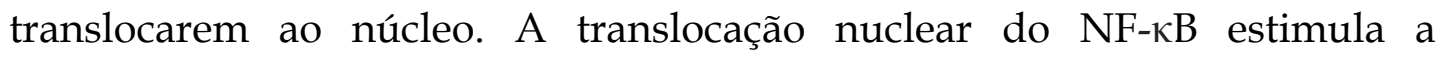
transcrição de genes que codificam mediadores pró-inflamatórios, como óxido nítrico (NO), prostaglandina E2 (PGE2) e citocinas, como fator de necrose tumoral (TNF) e interleucina $1 \beta$ (IL-1 $\beta$ ), entre outros (LU et al., 2008). 


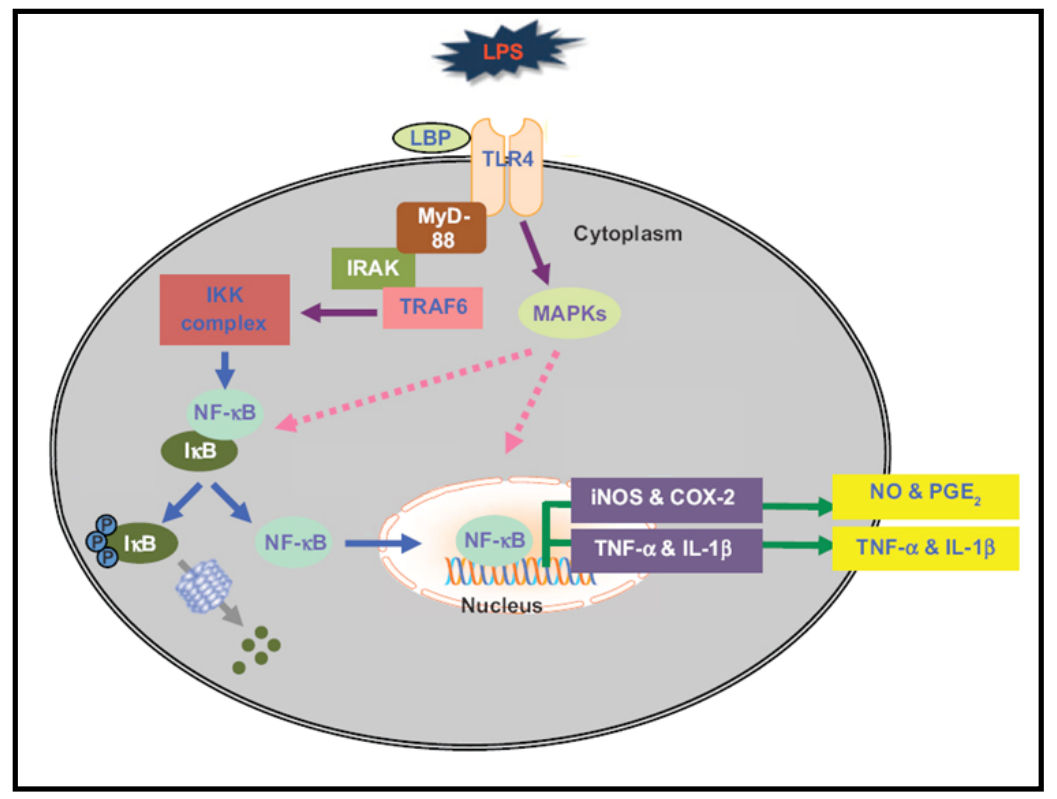

Figura 1 - Representação esquemática do mecanismo intracelular desencadeado pela ativação do receptor Toll-4 (TLR-4) por LPS. MyD88: (do inglês, myeloid differentiation primary response gene 88; IRAK: do inglês: IL-1 receptor-associated kinase; TRAF6: TNF receptor-associated fator 6; IKK: proteína quinase de IKB; IkB: proteína inibitória kappa B; NF-kB: fator de transcrição nuclear kappa B; iNOS: sintase de óxido nítrico induzida; COX-2: cicloxigenase-2, TNF: fator de necrose tumoral; IL-1 $\beta$ : interleucina 1 $\beta$; NO: óxido nítrico; PGE2: prostaglandina E2. Modificado de LU et al., 2008.

Estudos realizados com Rhinella paracnemis demonstraram que após a administração de LPS via sacos linfáticos, observa-se o desenvolvimento de febre comportamental - fenômeno relacionado a mudanças no sítio de termorregulação - por um mecanismo dependente da síntese de prostaglandinas (BICEGO et al., 2002; BICEGO-NAHAS et al., 2000; BRANCO \& MALVIN, 1996; BRANCO \& STEINER, 1999; VALGHN et al., 
1974). Outros estudos realizados com anfíbios também demonstraram que a admnistração de LPS pode acarretar uma elevação de $24 \%$ a 100\% da taxa metabólica desses indivíduos, o que poderia representar custo energético significativo e uma potencial fonte de compromissos funcionais de investimento em outras funções de relevância para o valor adaptativo (MUCHLINSKI, 1985; SHERMAM \& STEPHENS, 1998; LLEWELLYN et al., 2011). Neste sentido, recentemente demosntramos que o tratamento de machos com LPS elevou a temperatura preferencial de $23^{\circ} \mathrm{C}$ para $26^{\circ} \mathrm{C}$, caracterizando fenômeno de febre comportamental (MORETTI et al., 2016). Interessantemente, as taxas metabólicas de sapos administrados com LPS e deixados nestas duas temperaturas $\left(23^{\circ} \mathrm{C}\right.$ e $\left.26^{\circ} \mathrm{C}\right)$ foram equivalentes, sugerindo menor custo energético da resposta imune na temperatura febril (MORETTI et al., 2016)

Por fim, mudanças comportamentais são também identificadas na presença de citocinas pró-inflamatórias, como a inibição do comportamento reprodutivo, diminuição na atividade de forrageamento, anorexia e redução de ingestão de água (ASHLEY et al, 2012). Indivíduos de Rhinella marina apresentaram redução de ingestão de grilos e da atividade locomotora quando tratados com LPS (LLEWELLYN et al., 2011).

\section{Moduladores de processos de defesa dos organismos}

\section{Glicocorticóides}

A dinâmica de um processo de defesa envolve a ativação do eixo hipotálamo - hipófise - adrenal/interrenal. Em anfíbios, não há a formação 
de um córtex adrenal como ocorre em mamíferos. As células produtoras dos hormônios se misturam com os tecidos dos rins e células produtoras de catecolaminas, gerando dificuldade em isolar células adrenocorticais de células dos rins. Por esse motivo, o termo "glândula interrenal" se tornou bastante utilizado quando se trata de anfíbios (CARR \& NORRIS, 2005).

Em resposta a variações circadianas, estresse fisiológico e citocinas inflamatórias (IL-1 , por exemplo), o hipotálamo é estimulado a produzir o hormônio liberador de corticotropina (CRH) e arginina vasopressina (AVP) (Fgura 2). Estes hormônios atuam na hipófise anterior e induzem a síntese e secreção do hormônio adrenocorticotrópico (ACTH) que, lançados na circulação sanguínea, se ligam a receptores de melanocotina $\mathrm{MC}_{2}$, receptores de membrana acoplado à proteína Gs, cuja estimulação nas células adrenocorticais resulta em um aumento nos níveis intracelulares de AMPc e esteroidogênese (FONG et al., 2015). Durante o processo de síntese, a molécula de colesterol passa por uma série de transformações enzimáticas que são determinantes na produção de glicocorticoides, sendo o cortisol encontrado em humanos e a corticosterona em roedores e outros vertebrados. Os glicocorticoides, através da circulação sistêmica, se distribuem por todo o organismo e regulam negativamente o eixo hipotálamo-hipófise-adrenal através de um mecanismo de feedback sobre hipotálamo e hipófise e diminuição da expressão de citocinas próinflamatórias, como IL-1 $\beta$, IL-6 e TNF (CAIN \& CIDLOWSKI, 2017).

Em anfíbios adultos, corticosterona e aldosterona são os principais esteroides presentes na circulação (CARR \& NORRIS, 2005). Além disso, 
quantidades mensuráveis de epinefrina e norepinefrina são detectadas, com predomimância da norepinefrina (CARR \& ZOZZARO, 2004).

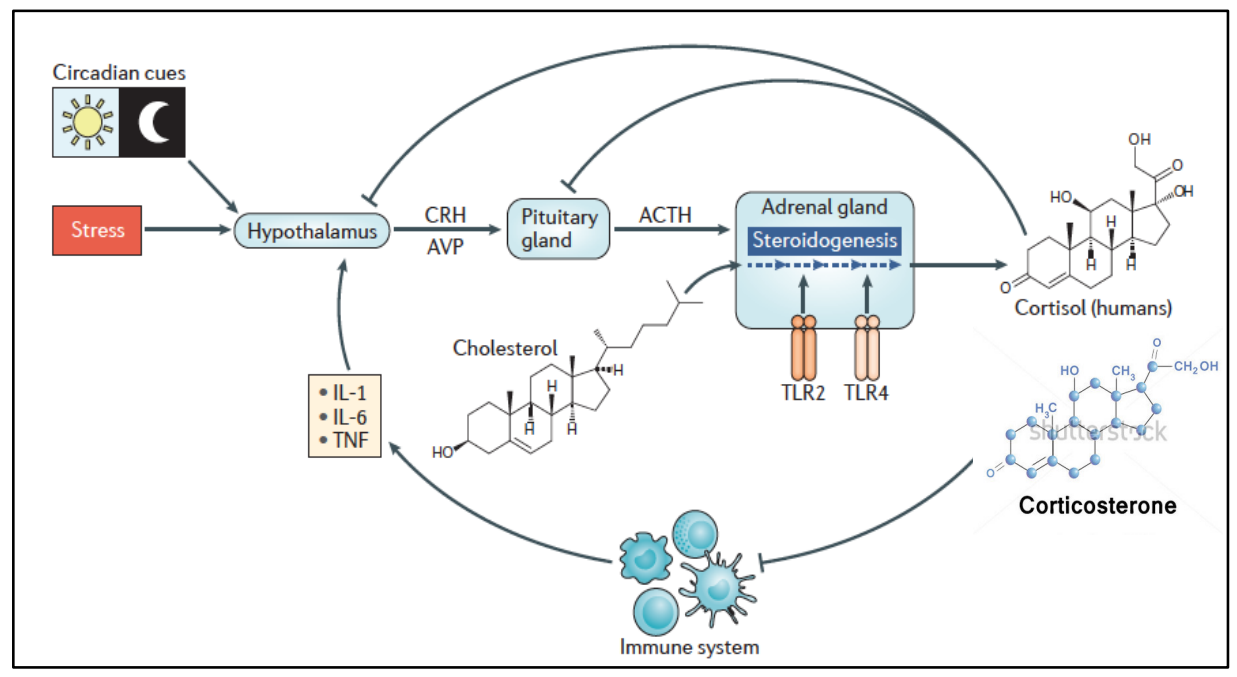

Figura 2 - Regulação do eixo hipotálamo-hipóse-adrenal sobre a produção de glicocorticóides pelo cótex da glândula adrenal/interrenal. CRH: hormônio liberador de corticotropina; AVP: arginina vasopressina; ACTH: hormônio adrenocorticotrópico; TLR2: receptor Toll2; TLR4: receptor Toll4; TNF: fator de necrose tumoral; IL-1: interleucina 1; IL-6: interleucina 6. Modificado de CAIN \& CIDLOWSKI (2017).

No espaço extracelular, os glicocorticoides endógenos são inativos devido à ligação com a proteína ligadora de corticosteróides (CBG; do inglês, corticosteroid-binding globulin). Cortisol/corticosterona não ligado é lipossolúvel e difunde-se através das membranas celulares. O glicocorticoide que entra no citoplasma pode ser convertido em cortisona inativa através de modificações enzimáticas pelas enzimas 11ß-hidroxiesteroide desidrogenase 2 (11ßHSD2) e 11ßHSD1 que favorece a reação inversa. A intercalação de cortisol nas membranas plasmáticas pode exercer efeitos não genômicos. $\mathrm{O}$ 
cortisol citoplasmático liga-se ao receptor de glicocorticoide (GR) formando um complexo chaperona. O GR ligado se transloca para o núcleo para exercer efeitos genômicos, ou tem efeitos não genômicos no citoplasma e mitocôndrias. No interior do núcleo, o GR ligado altera a expressão gênica através de três mecanismos básicos: ligação direta aos elementos de resposta do glicocorticoide (GRE; do inglês, glicocorticoid responsive elements) positivos ou negativos; interações proteína-proteína com outros fatores de transcrição (TFs) que afetam sua atividade transcricional; e ligação composta ao DNA e proteínas. Cada um desses mecanismos permite uma regulação gênica positiva e negativa (CAIN \& CIDLOWSKI, 2017) (Figura 3).

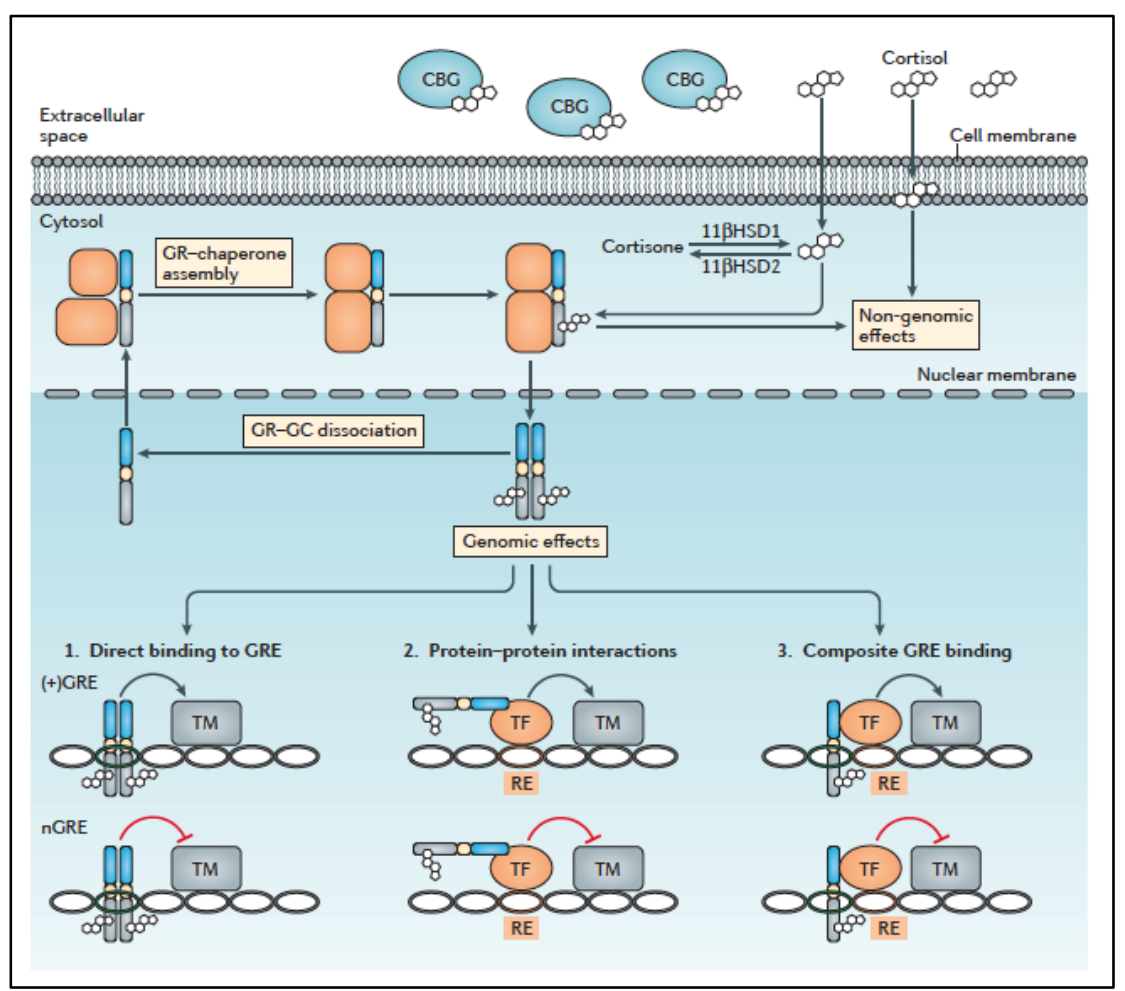

Figura 3 - Mecanismo de ação de glicocorticóides. CBG: proteína ligadora de corticosteroides; 11ß-HSD: 11ß-hidroxiesteroide desidrogenase; GRE: elemento responsivo ao glicocorticoide; TM: maquinaria transcricional; TF: fator de transcrição. CAIN \& CIDLOWSKI (2017). 
O aumento da secreção de glicocorticoides é uma clássica resposta endócrina ao estresse. Em resposta a agentes estressores, a secreção de glicocorticoides aumenta aproximadamente uma ordem de magnitude. $\mathrm{O}$ tipo e a duração do agente estressor utilizado varia consideravelmente e, sob essa perspectiva, define-se "estresse agudo" a forma de estresse causada por submissão a agente estressor por poucas horas. Se o agente estressor for repetido diariamente e por diversos dias - "estresse subagudo" e, se o mesmo persistir por semanas ou meses, caracteriza-se um estresse crônico (SAPOLSKY et al., 2000). Uma ativação temporária do eixo hipotálamohipófise-adrenal pode ter efeitos benéficos (WINGFIELD et al. 1997; WINGFIELD \& ROMERO, 2001), enquanto que, a ativação por longos períodos traz consequências nocivas e uma supressão da resposta imune passa a ser observada (SAPOLSKY, 1992; ROMERO \& WINGFIELD, 2001). Dentre os efeitos imunossupressores, podemos destacar a inibição da síntese e liberação de diversas citocinas e outros mediadores que promovem a resposta imune e reações inflamatórias, bem como a atrofia de tecidos linfoides, como o timo (WIEGERS \& REUL, 1998; SAPOLSKY et al. 2000).

Ativando o eixo hipotálamo-hipófise-adrenal a curto prazo e em baixa intensidade, alguns efeitos de reforço do sistema imune são observados, como o aumento da expressão de receptores para diferentes citocinas (WIEGERS \& REUL, 1998), bem como a redistribuição de células imunes no organismo, o que leva a um aumento de leucócitos na circulação, com eventual melhoramento na função imune de alguns órgãos (DHABHAR, 2009; MCCORMICK \& LANGKILDE, 2014). Esses estudos também 
detectaram mecanismos nos quais estressores agudos podem não só aumentar a imunidade inata, mas também a adaptativa. Tais mecanismos envolvem células dendríticas, neutrófilos, macrófagos e tráfico, maturação e função de linfócitos (DHABHAR, 2009; MCCORMICK \& LANGKILDE, 2014).

Em concordância com o exposto, Assis e colaboradores (2015) investigaram os efeitos da retenção por longo período em cativeiro, com ou sem restrição de movimentos, sobre a imunocompetência inata em Rhinella icterica. Os resultados demonstraram que $24 \mathrm{~h}$ de restrição de movimentos é uma situação estressante com induz o aumento dos níveis de corticosterona plasmática em três vezes, sem a constatação de mudanças imunológicas consistentes. Contudo, em animais que tiveram seus movimentos restritos em bolsas por $24 \mathrm{~h}$, houve a potenciação dessa resposta, com aumento de nove vezes dos níveis plasmáticos de corticosterona, além do aumento da relação neutrófilo/linfócito e diminuição da capacidade bactericida plasmática. A aplicação transdérmica de corticosterona, mimetizou os eventos de resposta aguda ao estresse, não sendo observadas mudanças nos parâmetros imunes mesmo após treze dias de tratamento. Este mesmo estudo demonstrou também que longo tempo em cativeiro não levou à diminuição da resposta ao estresse, sendo detectados níveis elevados de corticosterona mesmo depois de noventa dias em cativeiro. Cabe destacar que, um longo tempo em cativeiro nas mesmas condições, levou a um aumento da contagem total de leucócitos e um decréscimo na capacidade bactericida plasmática. Estes achados demonstram, portanto, que as 
consequências da resposta ao estresse para esta espécie podem, de fato, ser agravadas pelo tempo em cativeiro (ASSIS et al., 2015).

Em outro estudo, Gomes e colaboradores (2012) compararam os níveis de corticosterona basais e pós-estresse de contenção em três espécies de Bufonídeos, sendo elas Rhinella icterica, R. ornata e R. schneideri. Essas espécies são caracterizadas por diferentes graus de dependência a ambientes florestados. De acordo com essa pesquisa, $R$. ornata - espécie com maior grau de dependência de ambientes florestados - apresentou os maiores níveis de costicosterona basais e pós-estresse de contenção. $R$. schneideri - espécie com distribuição geográfica mais associada a áreas naturalmente abertas ou desmatadas - apresentou a maior capacidade bactericida plasmática. Os autores demonstraram também uma associação negativa interespecífica entre capacidade bactericida plasmática e os níveis basais de corticosterona nesses animais. Isso sugere que a menor imunocompetência das espécies de ambientes florestados poderia estar associada ao efeito imunosupressor da corticosterona, reduzindo suas chances de ocupar áreas naturalmente abertas ou desmatadas. Nesse mesmo estudo, verificou-se que, em R. ornata, os níveis basais de corticosterona são equivalentes ao encontrado em $R$. schneideri após estresse experimental de contenção.

Os glicocorticoides possuem, portanto, um efeito bimodal na resposta imune, onde esta poderá ser mediada por diferentes concentrações deste hormônio e, possivelmente, por diferentes receptores (WIEGERS et al. 1993; WIEGERS et al. 1995; WIEGERS \& REUL, 1998). 
Portanto, em resumo, os glicocorticoides, quando liberados, levam a alterações fisiológicas, metabólicas e comportamentais em resposta ao agente estressor (CARR \& NORRIS, 2005).

\section{Melatonina}

A melatonina (N-acetil-5-metoxitriptamina) tem se revelado como uma molécula de distribuição ubíqua e funcionalidade diversa. Em mamíferos, os mecanismos que controlam sua síntese na glândula pineal tem sido bem caracterizados e podem ser acompanhados na figura 4. Específicos comprimentos de onda são detectados através do fotopigmento melanopsina, presente em uma pequena proporção de células ganglionares da retina ( 1 a 2\%) cujos axônios projetam-se para os núcleos supraquiasmáticos (SCN) através do trato retinohipotlâmico (RHT). Estes neurônios liberam glutamato e polipeptídeo ativador de adenilil ciclase da pituitária (PACAP), os quais causam entrainment da expressão de genes do relógio no SCN. A atividade circadiana de células no SCN é uma função de mecanismos de retroalimentação autoregulatórios. Para modular a produção de melatonina pela pineal, neurônios do SCN projetam axônios para o núcleo paraventricular do hipotálamo (PVN) do hipotálamo onde liberam ácido aminogamabutírico (GABA). Corpos celulares de neurônios do PVN possuem axônios que descem através de tronco cerebral e coluna intermédio lateral (ILCC), que são neurônios pré-ganglionares simpáticos cujos terminais inervam os pinealócitos após uma sinapse no gânglio cervical superior. A liberação noturna de noradrenalina estimula a síntese e liberação 
de melatonina. A melatonina é liberada no sistema vascular sanguíneo e também no fluido cefalorraquidiano (CSF) do terceiro ventrículo. A melatonina sanguínea e do líquor tem livre acesso aos neurônios do SCN onde atuam em receptores metabotrópicos de melatonina MT1 e MT2, influenciando os disparos dos neurônios do SCN ajustando o relógio biológico e regulando os diversos ritmos endógenos dos organismos. (REITER et al., 2010)

A melatonina é sintetizada pela acetilação e metilação da serotonina, através da ação das enzimas arilalquilamina N-acetiltransferase (AA-NAT) e acetilserotonina-metil-transferase (ASMT), que levam à formação do precursor N-acetilserotonina (NAS) e melatonina, respectivamente (Figura 4). Em todos os vertebrados, a enzima-chave AA-NAT responde às informações fotoperiódicas e, em ectotérmicos, esta enzima é também responsiva à alterações de temperatura. De fato, em algumas espécies de vertebrados ectotérmicos, a temperatura é o principal regulador dos ritmos diário e sazonal de melatonina (DELGADO \& VIVIEN-ROELS, 1989; MASUDA et al., 2003).

Uma característica especial da melatonina está na variedade de mecanismos empregados para modular a fisiologia celular. A melatonina exerce suas ações fisiológicas pela interação com receptores de membrana MT1, MT2, MEL1c e proteínas intracelulares, como calmodulina, calreticulina e tubulina, além de uma relevante atividade antioxidante em várias células (BENITEZ-KING et al., 1993; DUBOCOVICH et al., 2005; PANDI-PERUMAL et al., 2008; JOCKERS et al., 2016). 


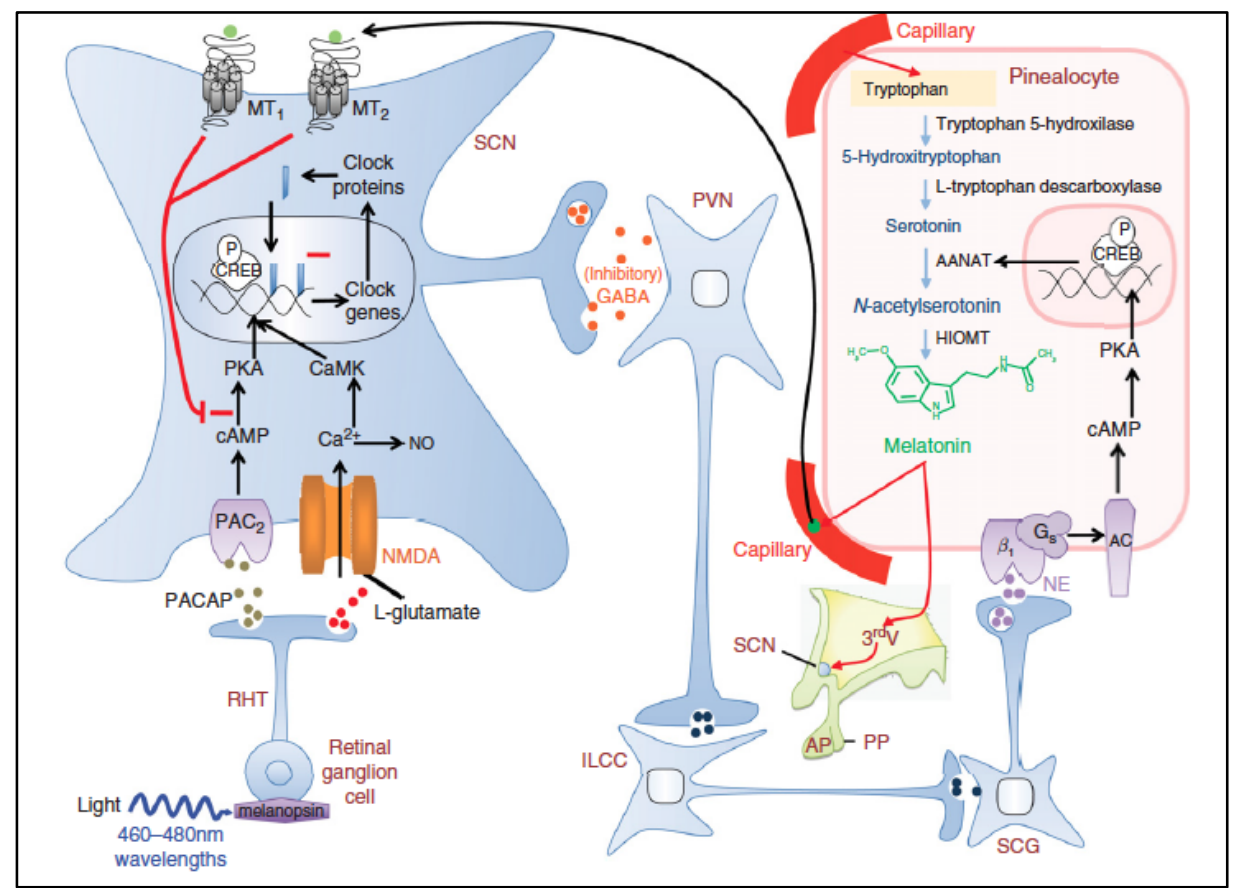

Figura 4 - Síntese de melatonina pela glândula pineal. AANAT: arilaquilamina $\mathrm{N}$-acetil transferase; AC: adeniliciclase; AP: hipófise anterior; $\beta 1$ : receptor beta-1 adrenérgico; CaMK: calmodulina quinase; cAMP: AMP cíclico; CREB: cAMP response-elementbinding protein; GS =G stimulatory protein; HIOMT/ASMT: hidroxi-indol-O-metiltransferase/acetil-serotonina-metiltransferase; NO: óxido nítrico; PKA: proteína quinase A; PP: hipófise posterior. Retirado de REITER et al., 2010.

Em anuros o sistema de temporização interna que controla a produção rítmica de melatonina é caracterizado por uma rede de sistemas interconectados que incluem: olhos, regiões encefálicas e a glândula pineal. Vários estudos anatômicos e estruturais indicam que a glândula pineal localiza-se numa área onde a calota óssea é fina sendo também envolta por tecidos menos pigmentados que facilitam, portanto, a percepção luminosa em ectotérmicos (Figura 5 ). 


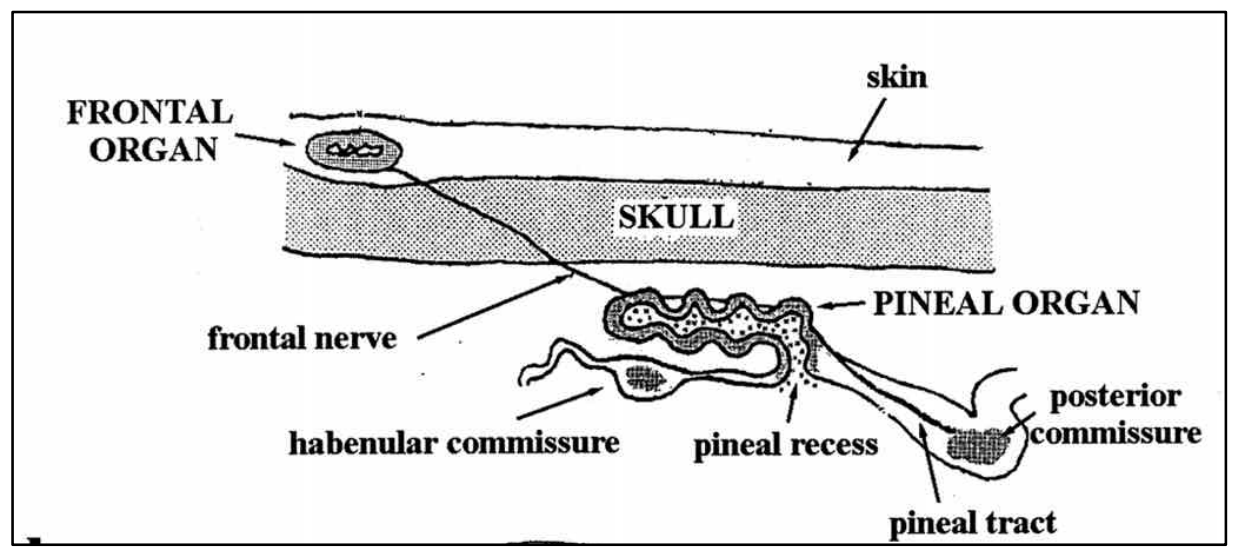

Figura 5 - Glândula pineal e estruturas associadas em anfíbios. Modificado de NORRIS, 2007.

Outra particularidade em relação à síntese de melatonina em ectotérmicos, refere-se ao fato de que a enzima chave na síntese de melatonina - AA-NAT, cuja sequencia de aminoácidos já foi clonada em anfíbios, responde à informação fotoperiódica como em todos os vertebrados e também a alterações de temperatura.

Por este amplo espectro de ações e ausência de toxicidade, a melatonina contribui para a melhora da fisiologia celular e dos organismos encontrando aplicações na medicina humana e veterinária (REITER et al., 2010).

Além das ações já citadas, a melatonina atua também na inibição da translocação nuclear de fatores de transcrição (CECON et al., 2010); em processos inflamatórios, potenciando a produção de interleucina 2 (IL-2), interleucina 6 (IL-6) e interferon gama (IFNY) em linfócitos e monócitos humanos (GARCIA-MAURIÑO et al., 1997) e participa ativamente na 
montagem e resolução de respostas inflamatórias (MARKUS et al., 2007). Como antioxidante, a melatonina possui capacidade tanto de sequestrar diretamente radicais livres quanto de potenciar a atividade de enzimas antioxidantes. Estes efeitos são gerados também por seus metabólitos, N1acetil-N2-formil-5-metoxiquinuramina $\quad$ (AFMK) $\quad$ e $\quad \mathrm{N}^{1}$-acetil-5metoxiquinuramina (AMK), moléculas com maior atividade antioxidante do que a própria melatonina, capazes de reagir diretamente com moléculas reativas, ROS e RNS (TAN et al., 2007).

A existência de uma interrelação entre as glândulas adrenal e pineal ficou estabelecida com a demonstração de um efeito dual da corticosterona ativando ou inibindo a síntese de melatonina pela pineal, na dependência dos níveis circulantes de corticosterona, ativação de GR e do padrão de ativação de receptores adrenérgicos (FERREIRA et al., 2005; FERNANDES et al., 2009; FERNANDES et. al., 2017). Uma análise de dados de vários laboratórios permitiu hipotetizar que, sob um estresse moderado, a informação hormonal noturna é reforçada, enquanto que sob um grande estresse o organismo perde a diferença hormonal entre o dia e a noite, reduzindo ou mesmo abolindo o pico noturno de melatonina (Figura 6). Os efeitos duais da corticosterona sobre a glândula pineal dependende do padrão de estimulação dos receptores adrenérgicos (FERNANDES et al., 2017). Altas concentrações de glicocorticoides aumentam a produção de melatonina quando a glândula está sob estimulação (FERREIRA et al., 2005, FERNANDES et al., 2009) e inibe a produção deste hormônio quando a estimulação é suficiente para ativar receptores $\alpha$ e $\beta$-adrenérgicos 
(YUWILLER et., 1989, FERNANDES et al., 2017). O mecanismo que envolve o efeito dual de glicocorticoides sobre a síntese de melatonina é, provavelmente, a habilidade deste hormônio em potenciar ou inibir a atividade da enzima-chave na síntese de melatonina (FERREIRA et al., 2005; YUWILER, 1989).

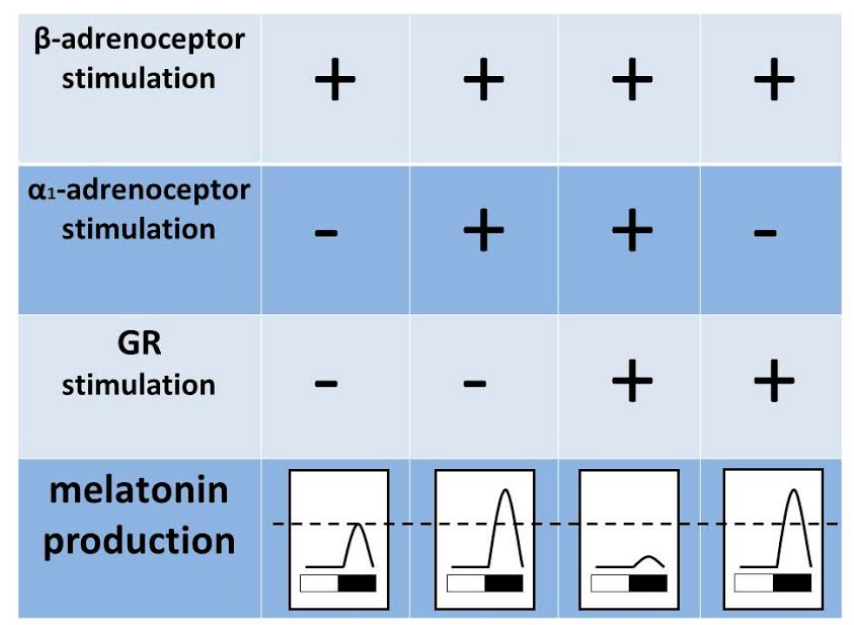

Figura 6 - Efeito da ativação de receptores adrenégicos e de glicocorticoide sobre a síntese de melatonina pela glândula pineal de mamíferos.

Outros agentes inflamatórios também são capazes de modular a via biossintética da melatonina. A citocina TNF, por exemplo, inibe a produção de melatonina e seu precursor $\mathrm{N}$-acetilserotonina em glândulas pineais em cultura por um mecanismo dependente da ativação da translocação nuclear de NF-kB e consequente bloqueio da transcrição da enzima AA-NAT (FERNANDES et al., 2006; CARVALHO-SOUSA et al., 2011).

O fator de transcrição NF-kB participa também na mediação dos efeitos de LPS, via receptores TLR-4 presentes na glândula pineal, levando à inibição da produção de melatonina induzida por noradrenalina em 
glândulas pineais em cultura (da SILVEIRA CRUZ-MACHADO et al., 2010). Recentemente, nosso grupo de pesquisa demonstrou também a participação desta via de sinalização na inibição da produção de melatonina por glândulas pineais em cultura estimuladas por peptídeo $\beta$-amiloide (CECON et al., 2015). Estes dados demonstram, portanto, a importância da sinalização

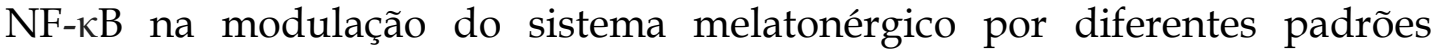
moleculares associados a patógenos (PAMPs) envolvidos em quadros infecciosos, presentes em bactérias (LPS), fungos e parasitas e a padrões moleculares associados a danos (DAMPs), moléculas endógenas como as citocinas pró-inflamatórias, moléculas da matriz extracelular apresentadas em concentração exacerbada, moléculas intracelulares, como DNA e proteínas chaperonas, dentre outras (MARKUS \& CECON, 2013). O entendimento dos mecanismos envolvidos com esta comunicação bidirecional entre o sistema melatonérgico e o sistema imunológico permitiu a descrição do eixo imune pineal (MARKUS et al., 2007). Neste contexto, o controle da produção de melatonina pela pineal por mediadores imunológicos resulta em um controle fino da migração de células imunocompetentes pelo endotélio vascular. Além disso, no local da lesão, a produção de melatonina por células imunológicas aumenta a capacidade destas células em regular a resposta de defesa (Figura 7). 


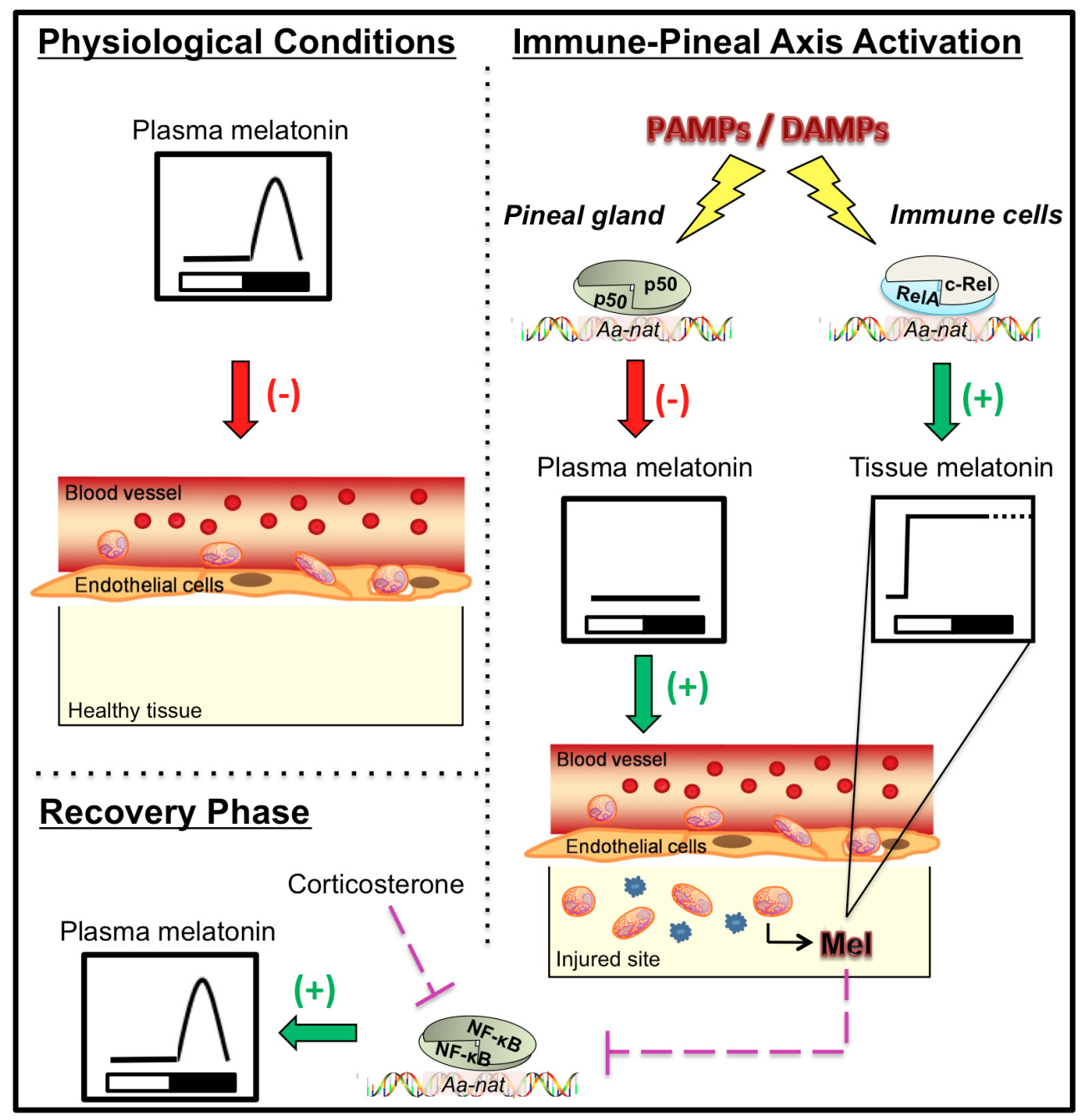

Figura 7 - Modulação do sistema melatonérgico por diferentes padrões moleculares associados PAMPs e DAMPs - participação da via de NF-кB.

Mecanismos de defesa associados à ativação de receptores de TLR4 regulam a resposta imune inata desde insetos até vertebrados (VILCEK \& LE, 1994, AKIRA \& TAKEDA, 2004; FAHEY et al., 2005; WIRA et al., 2005). Portanto, percebendo a importância da resposta ao estresse em anuros e conhecendo a ação inibitória do agente infeccioso LPS sobre a síntese de melatonina pela pineal de mamíferos, o objetivo do presente trabalho foi 
investigar os efeitos da inflamação sistêmica induzida por LPS sobre os níveis circulantes de citocinas, corticosterona e melatonina (neste caso também foi avaliado o conteúdo ocular) em machos de Rhinella icterica. $\mathrm{O}$ perfil circadiano de secreção hormonal de corticosterona e melatonina plasmática também foram determinados de modo a caracterizar a produção destes hormônios em indivíduos saudáveis. Sendo assim, as hipóteses levantadas neste trabalho acerca dos efeitos da inflamação sistêmica induzida pelo agente LPS foram:

1 - o aumento dos níveis plasmáticos de citocinas pro-inflamatórias;

2 - a ativação do eixo hipotálamo-hipófise-interrenal analisada através do aumento da produção de glicocorticoides pelas glândulas interrenais;

3 - a inibição da síntese de melatonina pela glândula pineal (mensuração no plasma) e também da melatonina ocular. 


\section{CONCLUSÕES}

Os resultados apresentados neste trabalho evidenciam em anuros da espécie Rhinella icterica:

1- $\quad$ O padrão temporal de produção e liberação dos hormônios corticosterona e melatonina, hormônios marcadores do período de atividade e escuro, respectivamente;

2- $\quad$ LPS é um importante indutor da resposta inflamatória levando a um aumento da liberação da citocina IL-1ß;

3- $\quad$ A indução da inflamação sistêmica por LPS ativa o eixo hipotálamo-hipófise-interrenal aumentando a produção de corticosterona pela glândula interrenal;

4- $\quad$ LPS atua como um PAMP e leva à inibição da síntese de melatonina plasmática e ocular.

Esses resultados sugerem existência de uma comunicação bidirecional entre os sistemas neuro-imuno-endócrino através das interações entre seus mediadores apontando, desta forma, para a existência do eixo imune-pineal ativo em anuros da espécie Rhinella icterica. Estímulos estressores como PAMPs/DAMPs modulam a atividade da glândula pineal ativando o eixo imune-pineal com conseguinte diminuição da síntese de melatonina e montagem da resposta inflamatória. 


\section{RESUMO}

Vários estressores, incluindo poluição e patógenos, têm contribuído para o declínio/extinção da população de anfíbios levantando a questão da necessidade de ampliar o conhecimento dos aspectos da imunidade inata destes animais. Este trabalho teve por objetivo investigar os efeitos da inflamação sistêmica induzida por LPS na produção de mediadores que participam da montagem e resolução de respostas inflamatórias em anfíbios anuros. Adultos machos da espécie Rhinella icterica coletados em Janeiro de 2015 (São Luiz do Paraitinga, SP, Brazil (Licença do IBAMA: 29896) foram mantidos individualmente em caixas plásticas com circulação de ar, $22 \pm 2^{\circ} \mathrm{C}$, LD 12:12h, água ad libitum e alimentados uma vez por semana com grilos e baratas. As variações diárias de CORT e MEL foram determinadas no plasma coletado durante $24 \mathrm{~h}$ por punção cardíaca. Para a indução de uma inflamação sistêmica, os animais foram injetados no saco linfático dorsal com solução salina ou LPS (de Escherichia coli, serotype 0127:B8; 2.0mg/Kg; ZT15) e eutanaziados após duas horas. O padrão temporal de liberação de CORT foi evidenciado pelos níveis aumentados no período de atividade dos animais, com pico de liberação na transição claro-escuro. O padrão temporal noturno de produção de MEL foi evidenciado atingindo um pico de liberação 6 h após a entrada do escuro. A inflamação sistêmica induzida por LPS levou a um aumento nos níveis da citocina IL-1 $\beta$, ativação do eixo hipotálamohipófise-interrenal com aumento de 10x nos níveis de CORT e uma diminuição no conteúdo de MEL plasmática e ocular. Desta forma, os dados 
apresentados evidenciam uma variação circadiana na produção dos hormônios CORT e MEL, ainda não demonstrados em Rhinella icterica, bem como a existência de um mecanismo regulatório bidirecional entre os sistemas imune e endócrino em anfíbios, apontando para a presença de um Eixo Imune-Pineal ativo no controle de processos patológicos em anfíbios tal como já demonstrado em mamíferos. 


\section{ABSTRACT}

Several stressors, including pollution and pathogens, have contributed to the decline/extinction of the amphibian population raising the question of the need to increase knowledge of the aspects of the innate immunity of these animals. This work aimed to investigate the effects of systemic inflammation induced by LPS on the production of mediators that participate in the assembly and resolution of inflammatory responses in amphibians. Male adults of the specie Rhinella icterica collected in January 2015 (São Luiz do Paraitinga, SP, Brazil (IBAMA License: 29896) were individually kept in plastic boxes with air circulation, $22 \pm 2{ }^{\circ} \mathrm{C}, \mathrm{LD} 12$ : $12 \mathrm{~h}$, water ad libitum and fed once a week with crickets and cockroaches.The daily variations of CORT and MEL were determined in plasma collected for $24 \mathrm{~h}$ by cardiac puncture.In order to induce a systemic inflammation, the animals were injected into the dorsal lymph sac with LPS (Escherichia coli, serotype 0127: B8, $2.0 \mathrm{mg} / \mathrm{kg}$, ZT15) and euthanized after two hours. The temporal pattern of CORT release was evidenced by the increased levels in the period of activity of the animals, with a peak release at the transition light/dark cycle. The nocturnal temporal pattern of MEL production was evidenced reaching a peak of release $6 \mathrm{~h}$ after the dark entrance. LPS-induced systemic inflammation led to an increase in the cytokine IL-1 $\beta$ levels, activation of the hypothalamic-pituitary-interrenal axis with a 10x increase in CORT levels and a decrease in plasma and ocular MEL content. Thus, the data presented evidence a circadian variation in the production of CORT and MEL 
hormones, not yet demonstrated in Rhinella icterica, as well as the existence of a bidirectional regulatory mechanism between the immune and endocrine systems in amphibians, pointing to the presence of an Immune-Pineal Axis active in the control of pathological processes in amphibians as already demonstrated in mammals. 


\section{REFERÊNCIAS}

AKIRA, S.; TAKEDA, K.. Toll-like receptor signalling. Nature Reviews Immunology. v. 4, n. 7, p. 499-511. 2004.

AOYAMA, H.; MORI, N. \& MORI, W. Anti-glucorticoid effects of melatonin on adult rats. Acta Pathol. Jpn. v. 37, p. 1143-1148. 1987.

ASHLEY, N.T.; WEIL, Z.M. \& NELSON, R.J. Inflammation: mechanisms, costs and natural variation. Annu Rev Ecol Evol Syst. v. 43, p. 385-406. 2012.

ASSIS, V.R.; TITON, S.C.M; BARSOTTI, A.M.G.; TITON JR, B.; GOMES, F.R. Effects of Acute Restraint Stress, Prolonged Captivity Stress and Transdermal Corticosterone Application on Immunocompetence and Plasma Levels of Corticosterone on the Cururu Toad (Rhinella icterica). PLoS One 10 (4): e0121005. doi:10.137/joumal.pone.0121005. 2015.

BARSANO. C.P. \& BAUMANN, G. Editorial: simple algebraic and graphic methods for the apportionment of hormone (and receptor) into bound and free hormone? Endocrinology. v. 124, p. 1101-1106. 1989.

BARSOTTI, A.M.G. Modulação dos níveis plasmáticos de corticosterona e imunocompetência em resposta ao tratamente exógeno com ACTH em Hypsiboas faber. Dissertação de Mestrado, Instituto de Biociências, USP, 2014.

BARSOTTI, A.M.G.; ASSIS, V.R.; TITON, S.C.M.; TITON JR, B.; FERREIRAZ, Z.F.S. \& GOMES, F.R. ACTH modulation on corticosterone, melatonin, testosterone and innate immune response in the tree frog Hypsiboas faber. Comparative Biochemistry and Physiology. v. 204(A), p. 177-184. 2017.

BENÍTEZ-KING， G.; HUERTO-DELGADILLO, L. \& ANTÓN-TAY, F. Binding of 3H-melatonin to calmodulin. Life Sci. v.53, p.201-207, 1993.

BERGER, L.; SPEARE, R.; DASZAK, P.; GREEN, D.E.; CUNNINGHAM, A.A.; GOGGIN, C.L., SLOCOMBE, R.; RAGAN, M.A.; HYATT, A.D.; 
McDONALD, K.R.; HINES, H.B., LIPS, K.R.; MARANTELLI, G. \& PARKES, H. Chytridiomycosis causes amphibian mortality associated with population declines in the rainforests of Australia and Central America. Proc Natl Acad Sci. v.95, p. 9031-9036. 1998.

BICEGO, K.C.; STEINER, A.A.; ANTUNES-RODRIGUES, J. \& BRANCO, L.G.S. Indomethacin impairs LPS-induced behavioral ferver in toads. J Appl Physiol. v.93, p.512-516. 2002.

BICEGO-NAHAS, K.C.; STEINER, A.A.; CARNIO, E.C.; ANTUNESRODRIGUES, J \& BRANCO, L.G.S. Antipyretic effect of arginine vasotocin in toads. Am J Physiol Regulatory Integrative Comp Physiol. v.278, p. R1408-R1414. 2000.

BRADFORD, D.F.; GRABER, D.M. \& TABATABAI, F. Populations declines of the native frog, Rana muscosa, in Sequoia and Kings Canyon National Parks, California. Southwestern Nat. v.39, p. 323-327. 1994.

BRANCO, L.G.S. \& MALVIN, G.M. Thermoregulatory effects of cyanide and azide in the toad, Bufo marinus. Am J Physiol Regulatory Integrative Comp Physiol. v.270, p. R169-R173. 1996.

BRANCO, L.G.S. \& STEINER, A.A. Central thermoregulatory effects of lactate in the toad Bufo paracnemis. Comp Biochem Physiol. v.122A, p. 457-461. 1999.

CAIN, D.W. \& CIDLOWSKI, J.A. Immune regulation by glucocorticoids. Nat Rev Immunol. v.17, p. 233-247, 2017.

CARR, J.A \& NORRIS, D.O. Immunohistochemical localization of corticotropin-releasing factor- and arginine vasotocin-like immunoreactivities in the brain and pituitary of the American bullfrog (Rana catesbeiana) during development and metamorphosis. Gen Comp Endocrinol. v. 78, p. 180-188. 1990.

CARR, J.A \& NORRIS, D.O. The hypothalamus-pituitary Axis. NORRIS, D.O. \& CARR, J.A (Eds.). "Endocrine Disruption: Biologic Bases for Health Effects in Wildlife and Humans". p. 58-86. Oxford University Press. 2005. 
CARR, J.A. \& ZOZZARO, P.E. The toad iris assay: a simple method for evaluating $\mathrm{CRH}$ action on the sympathetic nervous system. Gen Com Endocrinol. v. 135, p. 134-141. 2004.

CARVALHO-SOUSA C.E; DA SILVEIRA CRUZ-MACHADO, S; TAMURA E.K; FERNANDES, P.A; PINATO, L.; MUXEL, S.M; CECON, E. \& MARKUS, R.P. Molecular basis for defining the pineal gland and pinealocytes as targets for tumor necrosis factor. Front Endocrinol (Lausanne). v.2, p.10. 2011.

CAREY, C. Hypothesis concerning the cause $f$ the disappearance of boreal toads from the mountains of Colorado. Cons Biol. v.7, p. 355-362. 1993.

CECON, E.; FERNANDES, P.A.; PINATO, L.; FERREIRA, Z.S. \& MARKUS, R.P. Daily variation of constitutively activated nuclear factor kappa B (NF-kappaB) in rat pineal gland. Chronobiol Int. v.27, p.52-67, 2010.

CECON, E.; CHEN, M.; MARÇOLA, M.; FERNANDES, P.A; JOCKERS, R. \& MARKUS, R.P. Amyloid peptide directly impairs pineal gland melatonin synthesis and melatonin receptor signaling through the ERK pathway. FASEB J. v.29, p. 2566-82. 2015.

CHEN, H.Y.; CHEN, T.Y.; LEE, M.Y.; CHEN, S.T.; HSU, Y.S.; KUO, Y.L.; ... \& LEE, E.J. Melatonin decreases neurovascular oxidative/nitrosative damage and protects against early increases in the blood-brain barrier permeability after transient focal cerebral ischemia in mice. Journal of Pineal Research. v. 41(2), p. 175-182. 2006.

CONDEZ, T. H, SAWAYA, R.J. \& DIXO, M. Herpetofauna of the Atlantic Forest remmants of Tapiraí and Piedade region, São Paulo, southeastern Brazil. Biota Neotrop. v.9(1). 2009.

CUNNINGHAM, A.A.; LANGTON, T.E.S.; BENNET, P.M.; LEWIN, J.F.; DRURY, S.E.N.; GOUGH, R.E. \& MACGREGOR, S.K. Pathological and microbiological findings form incidents of unusual mortality of the common frog (Rana temporaria). Phil Trans R Soc Lond B. v. 351, p. 15391557. 1996. 
DELGADO, M.J. \& VIVIEN-ROELS, B. Effect of environmental temperature and photoperiod on the melatonin levels in the pineal, lateral eye, and plasma of the frog, Rana perezi: importance of ocular melatonin. Gen. Comp. Endocrinol. v.75, p.46-53. 1989.

DHABHAR, F.S. Enhancing versus suppressive effects of stress on immune function: Implications for immunoprotection ande immunopathology. Neuroimmunomodul. v16, p.300-317. 2009.

DUBOCOVICH, M.L. \& MARKOWSKA, M. Functional MT1 and MT2 melatonin receptors in mammals. Endocrine. v.27(2), p.101-10. 2005.

ESCAMES, G., LEÓN, J., MACÍAS, M., KHALDY, H. \& ACUÑACASTROVIEJO, D. Melatonin counteracts lipopolysaccharide-induced expression and activity of mitochondrial nitric oxide synthase in rats. FASEB Journal v.17, p. 932-934. 2003.

FAHEY, J.V; SCHAEFER, T.M; CHANNON, J.Y \& WIRA, C.R. Secretion of cytokines and chemokines by polarized human epithelial cells from the female reproductive tract. Hum Reprod. v. 20. p. 1439-1446. 2005.

FERNANDES, P.A.C.M. Regulação da produção hormonal da glândula pineal de ratos por moduladores do processo inflamatório. Tese de Doutorado, Instituto de Biociências, USP, 2009.

FERNANDES, P.A.; CECON, E.; MARKUS, R.P. \& FERREIRA, Z.S. Effect of TNF-alpha on the melatonin synthetic pathway in the rat pineal gland: basis for a "feedback" of the immune response on circadian timing. $\mathbf{J}$ Pineal Res. v.41, p. 344-350. 2006.

FERNANDES, P.A.; BOTHOREL, B.; CLESSE, D.; MONTEIRO, A.W.; CALGARI, C.; RAISON, S.; SIMONNEAUX, V. \& MARKUS, R.P. Local corticosterone infusion enhances nocturnal pineal melatonin production in vivo. J Neuroendocrinol. v. 21, p. 90-97. 2009.

FERREIRA, Z.S.; FERNANDES, P.A.C.M.; DUMA, D.; ASSREUY, J.; AVELLAR, M.C.W. \& MARKUS, R.P. Corticosterone modulates 
noradrenaline-induced melatonin synthesis through inhibition of nuclear factor kappaB. J Pineal Res. v.38, p.182-88. 2005.

FONG, T. M.; SCHIOTH, H.; GANTZ, I.; CONE, R. D.; FAROOQI, S.; HASKELL-LUEVANO, C.; HRUBY, V. J.; MOUNTJOY, K. G.; TATRO, J. B.; WISKBERG, J. E. S.. Melanocortin receptors: MC2 receptor. Last modified on 16/06/2015. Accessed on 30/08/2017. IUPHAR/BPS Guide to

PHARMACOLOGY. http://www.guidetopharmacology.org/GRAC/ObjectDisplayForward? objectId $=283$

FROST, D. R. 2017. Amphibian Species of the World: an online reference. Version 6 (28/08/2017). Electronic Database accessible at http://research.amnh.org/herpetology/amphibia/index.html. American Museum of Natural History, New York, USA.

GARCIA-MAURIÑO, S.; GONZALEZ-HABA, M.G.; CALVO, J.R.; RAFII-ELIDRISSI, M.; SANCHEZ-MARGALET, V.; GOBERNA， R. \& GUERREIRO, J.M. Melatonin enhances IL-2, IL-6, and IFN-gamma production by human circulating CD4+ cells: a possible nuclear receptormediated mechanism involving $\mathrm{T}$ helper type 1 lymphocytes and monocytes. J Immunol. v.159, p.574-81. 1997.

GOMES, F.R.; OLIVEIRA, R.V.; ASSIS, V.R; TITON JR, B.; MORETTI, E.H. \& MENDONÇA, M.T. Interespecific variation in innate immune defenses and stress response of toads from Botucatu (São, Paulo, Brazil). South Amer J Herpet. v.7, p.1-8. 2012.

GUILLETTE, L.; CREE, A; ROONEY, A. Biology of stress: interactions with reproduction, immunology and intermediary metabolism. In: Warwick, C.; Frye, F; Murphy, J. (Eds.) Health and welfare of captive reptiles. Chapman and Hall, London. p. 32-81. 1995.

HOROWITZ, M.C. Cytokines and estrogen in bone: anti-osteoporotic effects. Science. v. 260, p. 626-627. 1993. 
ISORNA, E.; BESSEAU, L.; BOEUF, G.; DESDEVISES, Y.; VUILLEUMIER, R.; ALONSO-GÓMEZ, A.L.; DELGADO, M.J. \& FALCÓN, J. Retinal, pineal and diencephalic expression of frog arylalkylamine N-acetyltransferase1. Mol Cell Endocrinol. v.252 (1-2), p.11-8. 2006.

JESSOP, T.S; COLIN, J.L; WHITTIER, J.M. Nocturnal activity in the green sea turtle alters daily profiles of melatonin and corticosterone. Horm Behav. v.41, p. 357-365. 2002.

JESSOP, T.S.; DEMPSTER, T.; LETNIC, M. \& WEBB, J.K. Interplay among nocturnal activity, melatonin, corticosterone and performance in the invasive cane toad (Rhinella marinus). Gen Comp Endocrinol. v. 206, p. 43-50. 2014.

JOCKERS R, DELAGRANGE P, DUBOCOVICH ML, MARKUS RP, RENAULT N, TOSINI G, CECON E, ZLOTOS DP. Update on melatonin receptors: IUPHAR Review 20. Br J Pharmacol. v.173, p. 2702-25. 2016.

KLUGER, M.J. Fever: role of pyrogens and cryogens. Physiol Rev. v.71, p. 93-127. 1991.

LANCE, V. A; Stress in reptiles. In: Epple, A.; Scanes, C.G.; Stetson, M.H. (Eds.) Prospects in Comparative Endocrinology, Wiley-Liss, New York. p. 461-466. 1990.

LLEWLLYN, D.; BROWN, G.P.; THOMPSON, M.B. \& SHINE, R. Behavioral responses to immune-system activation in an anuran (the cane toad, Bufo marinus) field and laboratory studies. Physiol Biochem Zoo. v. 84, p. 7786. 2012.

LOPES, C.; MARIANO, M. \& MARKUS, R.P. Interaccion between the adrenal ande the pineal gland in chronic experimental inflammation induced by BCG in mice. Inflamm Res. v.50, p. 6-11. 2001.

MACIEL, N.M.; COLLEVATTI, R.G.; COLLI, G.R. \& SCHWARTZ, E.F. Late Miocene diversification and phylogenetic relationships of the huge toads in the Rhinella marina (Linnaeus, 1758) species group (Anura: Bufonidae). 
Mol Phylogenet Evol. v. 57, p. 787-797. DOI 10.1016/J.YMPEV.2010.08.025 PMID 20813190. 2010.

MARKUS, R.P. \& CECON, E. O tempo biológico e a defesa do organismo: uma conversa bidirecional entre a glâdula pineal e o sistema imunológico. Ciência e Cultura. v.61(1), p.52-55. 2013.

MARKUS, R.P.; FERREIRA, Z.S.; FERNANDES, P.A. \& CECON, E. The immune-pineal axis: a shuttle between endocrine and paracrine melatonin sources. Neuroimmunomodulation. v. 14, p. 126-133. 2007.

MASUDA, T.; IIGO, M.; MIZUSAWA, K.; NARUSE, M.; OISHI, T.; AIDA, K. \& TABATA, M. Variations in plasma melatonin levels of the rainbow trout (Oncorhynchus mykiss) under various light and temperature conditions. Zool. Sci. v.20, p.1011-1016. 2003.

MATSUKI, Y.; YAMAMOTO, T. \& HARA, K. Interleukin-1 mRNAexpressing macrophages in human chronically inflamed gingival tissues. Am J Pathol. v. 138, p. 1299-1305. 1991.

MATSUKI, Y.; YAMAMOTO, T. \& HARA, K. Detection of inflammatory cytokine messenger RNS (mRNA) - expressing cells in human inflamed gingiva by combined in situ hybridization and immunohistochemistry. Immunology. v. 76, p. 42-47. 1992.

MAYO, J.C, SAINZ, R.M, TAN, D.X, HARDELAND, R., LEÓN, J., RODRIGUEZ, C. \&REITER, R.J. Anti-inflamatory actions of melatonin and its metabolities, N1-acetyl-N2-formyl-5-methoxykynuramine (AFMK) and N1-acetyl-5-methoxykynuramine (AMK) in macrophages. J. Neuroimmunology. v. 165, p.139-149. 2005.

McCORMICK, G.L. \& LANGKILDE, T. Immune responses of eastern fence lizards (Sceloporus undulatus) to repeated acute elevation of Corticosterone. Gen Comp Endocrionol. v.204, p. 135-140, DOI 10.1016/j.ygcen.2014.04.037 PMID 24852352. 2014.

MENAKER, M. Eyes - the second (and third) pineal glands? Ciba Foundation Symposium v. 117, p. 78-92. 1985. 
MOORE, I.T. \& JESSOP, T.S. Stress, reproduction and adrecortical modulation in amphibians and reptiles. Horm Beh. v.43, p. 39-47. 2003.

MORETTI, E.H. Relação entre preferência termal, taxa metabólica e desafio imunológico por lipopolissacarídeo de bactéria gram-negativa (LPS) em Rhinella icterica (Anura: Bufonidae). Tese de Doutorado, Instituto de Biociências, USP, 2016.

MUCHLINSKI, A.E. The enrgetic cost of the fever response in three species of ectothermic vertebrates. Comp Biochem Physiol A Comp Physiol. v. 81, p. 577-579. 1985.

NORRIS, D.O. Comparative aspects of vertebrate reproduction. In: Norris, D.O. (Ed.), Vertebrate Endocrinology, $4^{\mathrm{a}}$ Ed Elsevier, p. 371-426. 2007.

PANDI-PERUMAL, S.R.; TRAKHT, I.; SRINIVASAN, V.; SPENCE, D.W.; MAESTRONI, G.J.; ZISAPEL, N. \& CARDINALI, D.P. Physiological effects of melatonin: role of melatonin receptors and signal transduction pathways. Prog Neurobiol. v.85(3), p. 335-53. 2008.

PERREAU, V.M; BONDY, S.C; COTMAN, C.W; SHARMAN, K.G \& SHARMAN, E.H. Melatonin treatment in old mice enables a more youthful response to LPS in the brain. J of Neuroimmunology v. 182, p. 22-31, 2007.

PETRILLI, C.L. Regulação da atividade da glândula pineal por estimulação purinérgica. Dissertação de Mestrado, Instituto de Biociências, USP, 2012.

QIN, H.; WILSON, C.A; LEE, S.J; ZHAO, X \& BENVENISTE, E.N. LPS induces $\mathrm{CD} 40$ gene expression through the activation of NF-kappaB and STAT-1alpha in macrophages and microglia. Blood v. 106(9), p. 31143122. 2005.

REGUERA, E. Regulación de las variaciones estacionales en la sensibilidad testicular a la acción de los glucorticoides en Rhinella arenarum (Amphibia, Anura). Interrrelación testículo-interrenal. Tese de Doutorado, Facultad de Ciencias Exactas y Naturales, UBA, 2012. 
REITER, R.J., TAN, D.X., FUENTES-BROTO, L. Melatonin: a multitasking molecule. Prog. Brain Res. v. 181, p.127-51. 2010.

ROMERO, L.M \& REED, J.M. Collecting baseline corticosterone samples in the field: is under 3 min good enough? Comp Biochem Physiol A Mol Integr Physiol. v. 140, p.73-9. 2005.

SABBAN, E.L.; NAKOVA, B.B.; SEROVA, L.I.; KVETNANSKY, R. \& LIU, X. Molecular regulation of gene expression of catecholamine biosynthetic enzymes by stress: sympathetic ganglia versus adrenal medulla. Ann $\mathbf{N}$ Y Acad Sci. v. 1018(1), p. 370-377. 2004.

SAPOLSKY, R. M. Stress, the aging brain and the mechanisms of neuron death. Cambridge, MA: MIT Press. 1992.

SAPOLSKY, R.M.; ROMERO, L.M. \& MUCK, A.U. How do glucocorticoids influence stress responses? Integrating permissive, suppressive, stimulatory, and preparative actions. Endocrinol. Rev. v21, p. 55-89. 2000.

SHERMAN, E. \& STEPHENS, A. Fever and metabolic rate in the toad Bufo marinus. J Therm Biol. v. 23, p. 49-52. 1998.

da SILVEIRA CRUZ-MACHADO S, CARVALHO-SOUSA CE, TAMURA EK, PINATO L, CECON E, FERNANDES PA, DE AVELLAR MC, FERREIRA ZS, MARKUS RP. TLR4 and CD14 receptors expressed in rat pineal gland trigger NFKB pathway. J Pineal Res. v.49, p. 183-92. 2010.

SOUZA-TEODORO, L. Caracterização do receptor P2X7 na fisiologia e na fisiopatologia da glândula pineal de ratos. Dissertação de Mestrado, Instituto de Biociências, USP, 2013.

TAN, D.X.; MANCHESTER, L.C.; TERRON, M.P.; FLORES, L.J. \& REITER, R.J. One molecule, many derivatives: a never-ending interaction of melatonin with reactive oxygen and nitrogen species? J Pineal Res. v.42, p.28-42. 2007.

TAN, D.X; HARDELAND, R.; MANCHESTER, L.C; PAREDES, S.D; KORKMAZ, A.; SAINZ, R.R; MAYO, J.C; FUENTES-BROTO, L. \& 
REITER, R.J. The changing biological roles of melatonin during evolution: from an antioxidant to signals of darkness, sexual selection and fitness. Biol.Rev. v. 85, p. 607-623. 2010.

TATAKIS, D.N. Interleukin-1 and bone metabolism: a review. J Periodontol. v. 64, p. 416-431. 1993.

TAYLOR, S.K.; WILLIAMS, E.S.; THORNE, E.T.; MILLS, K.W. \& WITHERS, D.I. Causes of mortality of the Wyoming toad (Bufo baxteri). J Wildlife Diseases. v.35, p.49-57. 1999.

TSAI, S.Y. \& MCNULTY, J.A. Interleukin-1beta expression in the pineal gland of the rat. J Pineal Res. v.27, p. 42-48. 1999.

TSAI, S.Y; SCHLUNS, K.S; LE, P.T \& MCNULTY, J.A. TGF-beta1 and IL-6 expression in rat pineal gland is regulated by norepinephrine and interleukin-1beta. Histol Histopathol. v. 16, p. 1135-1141. 2001 a.

TSAI, S.Y.; O'BRIEN, T.E. \& MCNULTY, J.A. Microglia play a role in mediating the effects of citokines on the structure and function of the rat pineal gland. Cell Tissue Res. v. 303, p.423-431. 2001b.

TYRELL, C.L. \& CREE, A. Relationship between corticosterone concentration and season, time of day and confinement in a wild reptile (tuatara, Sphenodon punctatus). Gen Comp Endocrinol. v.110, p. 97-108. 1998.

VAUGHN, L.K.; BERNHEIM, H.A. \& KLUGER, M.J. Fever in the lizard Dipsosaurus dorsalis. Nature v.252, p. 474-475. 1974.

VIGNALI, D.A. Multiplexed particle-based flow cytometric assays. J Immunol Methods. v. 243, p. 243-255. 2000.

VILCEK, J. \& LE, J. Immunology of cytokines: an introduction. In: Thomson, A. (Ed.). The Cytokine Handbook. Academy Press London. p. 1-19. 1994.

VITT, L.J \& CALDWELL, J.P. Herpetology: an introductory biology of amphibians and reptiles. $3^{\text {a }}$ edição. Academic Press. Burlington Massachusetts, EUA. 2009. 
YUWILER, A. Effects of steroids on serotonin-N-acetyltransferase activity of pineals in organ culture. J Neurochem. v.52, p. 46-53. 1989.

WIEGERS, G.J.; CROISET, G.; REUL, J.M.H.M.; HOLSBOER, F. \& DE KLOET, E.R. Differential effects of corticosteroids on rat peripheral blood T-lymphocyte mitogenesis in vivo and in vitro. Am J Physiol v.265, p. E825-E830. PMID 8279536. 1993.

WIEGERS, G.J.; LABEUR, M.S.; STEC, I.E.M.; KLINKERT, W.E.F.; HOLSBOER, F. \& REUL, M.H.M. Glucocorticoids accelerate anti-T cell receptor-inducetT cell growth. J Immunol. v. 155, p.1893-1902. PMID 7636240.1995.

WIEGERS, G.J. \& REUL, J.M.H.M. Induction of cytokine receptors by glucocorticoids: functional and pathological significance. Trends Pharmacol. Sci. v.19, p. 317-321. 1998.

WINGFIELD, J.C; HUNT, K.; BREUNER, C.; DUNLOP, K.; FOWLER, G.S; FREED, L. \& LEPSON, J. Environmental stress, field endocrinology, and conservation biology. In: Behavioral approaches to conservation in the wild: $\mathrm{p}$. 95-131. Clemmons, J. R. \& Buchholz, R. (Eds.). Cambridge: Cambridge University Press. 1997.

WINGFIELD, J.C \& ROMERO, L.M. Adrenocortical responses to stress and their modulation in free-living vertebrates. Comprehensive Physiology. p. 211-234. 2001

WIRA, CR.R; GRANT-TSCHUDY, K.S \& CRANE-GODREAU, M.A. Epithelial cells in the female reproductive tract: a central role as sentinels of immune protection. Am J Reprod Immunol. v.53, p. 65-76. 2005.

WITHYACHUMNARNKUL, B.; NONAKA, K.O; ATTIA, A.M \& REITER, R.J. Changes in indole metabolism in organ cultured rat pineal glands induced by interferon-gamma. J Pineal Res. v.8, p. 313-322. 1990.

WITHYACHUMNARNKUL, B.; REITER, R.J.; LERCHL, A.; NONAKA, K.O \& STOKKAN, K.A. Evidence that interferon-gamma alters pineal 
metabolism both indirectly via sympathetic nerves and directly on the pinealocytes. Int. J. Biochem. v. 23, p. 1397-1401. 1991.

WRIGHT, M.L. \& BRUNI, N.K. Influence of the photocycle and termocycle on rhythms of the plasma thyroxine and plasma and ocular melatonin in late metamorphic stages of the bullfrog tadpole, Rana castesbeiana. Comparative Biochemistry and Physiology, v.139(A), p.33-40. 2004.

WRIGHT, M.L.; RZASA, B.A.; WEIR, R.J.; BABSKI, A.M. Influence of cortisol on the larval bullfrog thyroid axis in vitro and in vivo and on plasma and ocular melatonin. Gen Comp Endocrinol. v. 116, p. 249-60. 1999. 